\title{
Minority Stress, Campaign Messages and Political Participation during the Australian Marriage Plebiscite
}

\author{
Sebastian E. Bartos ${ }^{1}$ - Daniel W. Noon ${ }^{2}$ - David M. Frost ${ }^{3}$ \\ Published online: 14 April 2020 \\ (C) The Author(s) 2020
}

\begin{abstract}
Background The health and wellbeing of sexual minorities is adversely impacted by a set of factors collectively known as minority stress. Recently, negative campaigns preceding gay-rights referenda have put further pressure on sexual minorities. However, active participation in political campaigns is expected to foster wellbeing. This study explores the mechanisms through which political campaigns affect psychological distress in sexual minorities.

Method We conducted a survey with 318 Australian sexual minority individuals during the campaign for the same-sex marriage postal vote in 2017.

Results As expected, exposure to negative campaign messages was associated with psychological distress. This association persisted controlling for the effects of everyday stress. The effect of exposure to negative campaign messages was no longer significant when controlling for minority stressors like internalized homophobia, expectations of rejection, and everyday discrimination. Political participation was also associated with psychological distress. Post hoc analyses supported a model whereby minority stressors mediated the associations of campaign messages and political participation with distress.

Conclusion Minority stress provides a flexible theoretical framework that can incorporate novel challenges to the wellbeing of sexual minorities.

Policy Implication As public votes on the rights of sexual minorities become more common, it is important to develop models that can inform policy in protecting such minorities.
\end{abstract}

Keywords Minority stress $\cdot$ Referendum $\cdot$ Gay rights $\cdot$ Political participation $\cdot$ Collective action

Same-sex marriage has been legislated in several countries, and such legislation was generally preceded by debates and political campaigns (e.g., for a book-long account of the referendum in Ireland, see Healy, Sheehan, \& Whelan, 2015). In 2017, the Australian government has conducted a postal survey (i.e., a non-binding public vote similar to a referendum) asking its citizens whether the law should be reformed to allow marriage for same-sex couples (Australian Bureau of Statistics, 2017). With a response of almost $80 \%$ and $62 \%$ national support for the reform, the survey ending on 5 November 2017 has generally been

Sebastian E. Bartos

Sebastian.Bartos@northampton.ac.uk

1 Division of Psychology, University of Northampton, Waterside Campus, room LH301, Northampton NN1 5PA, UK

2 School of Psychology, University of Sussex, Falmer, Brighton, UK

3 Department of Social Science, University College London, London, UK regarded as a success for the LGB (lesbian, gay, and bisexual) rights movement. Before the postal survey, same-gender couples in Australia could be recognized as having a de facto relationship (Same-Sex Relationships [Equal Treatment in Commonwealth Laws-Superannuation] Act 2008), based on a set of criteria, "as may seem appropriate to the court in the circumstances of the case" (Family Law Act, 1975, sect 4AA). The outcome of the survey prompted the legislation of equal marriage later that year, allowing same-gender couples to marry and divorce under the same conditions as heterosexual couples (Marriage Amendment [Definition and Religious Freedoms] Act 2017). However, the survey itself has been criticized, often based on the presumed impact it would have on LGB Australians. "You shouldn't have had to put up with this survey, but you've embraced it," Australian opposition leader Bill Shorten noted in his speech after the Yes victory. This narrative was common in the Australian media: sexual minorities faced an undue challenge in the plebiscite, but they found a constructive way of dealing with this challenge. The present study aims to assess the scientific merit of such a theory with data from a survey conducted during the last month of the postal vote (October-November 2017). 
In the following sections, we review the theoretical bases of claims about stress and resilience in the face of marriage referenda. First, we overview the evidence for the adverse effects of political campaigns. Second, we argue that the minority stress model provides a theoretical framework within which to make sense of the ill effects of marriage referenda. Third, we review the literature on political participation and communities as potential moderators of the association between minority and wellbeing. Finally, we predict that exposure to negative campaign messages during an equal marriage plebiscite is related to psychological distress in sexual minorities above and beyond everyday stress and other minority stressors; and that political participation mitigates these harmful effects.

\section{Negative Campaign Messages}

Anti-gay politics are likely to be stressful for those who are personally affected (Herek, 2011). Laws banning same-gender marriage are associated with higher levels of psychological distress in American LGB adults (Hatzenbuehler, McLaughlin, Keyes, \& Hasin, 2010; Rostosky, Riggle, Horne, \& Miller, 2009). Not just anti-gay laws, but political campaigns for changes in laws affecting LGB people may also be stressful and potentially damaging to their health and wellbeing (Flores, Hatzenbuehler, \& Gates, 2018; Frost \& Fingerhut, 2016). This may happen because proposed changes to laws regarding LGB rights call into question their value as full members of society and place their rights up for debate. Indeed, exposure to negative campaign messages decreased emotional and relational wellbeing in a small sample of American same-sex couples (Frost \& Fingerhut, 2016) during a recent wave of state-level marriage referenda. The same effect was found in two large Australian samples during the postal vote campaign we study in this paper (Ecker, Riggle, Rostosky, \& Byrnes, 2019; Verrelli, White, Harvey, \& Pulciani, 2019). However, we know relatively little about the extent and mechanisms of this effect.

\section{Minority Stress}

One potential explanation for the association between exposure to negative discourses surrounding the rights of LGB people and undesirable outcomes can be found in the minority stress model (Frost, 2020; Frost \& Fingerhut, 2016). The minority stress model, originally proposed by Meyer (1995, 2003), contends that exposure to unique forms of social stress stemming from stigma places LGB people at greater risk for mental and physical health problems relative to their heterosexual peers (who do not experience stigma based on their sexual orientation). Specifically, LGB people may experience a multitude of social stressors as a result of their stigmatized and disadvantaged social status, including prejudice-related life events (e.g., being fired from a job, attacked, or victimized); chronic and everyday forms of discrimination (e.g., receiving poorer services in stores, avoided, or slighted); expectations of rejection (e.g., stress related to anticipating discrimination regardless of whether it happens); concealment and disclosure related stress (e.g., having to hide one's sexual orientation in order to avoid rejection and discrimination); and internalized stigma (e.g., devaluing one's own self, and thinking one is less valuable to society). These minority stressors have been described as existing on a continuum of proximity to the self (Meyer, 2003), with distal stressors perpetrated by others and institutions (e.g., discrimination) leading to more proximal stressors such as the expectation of rejection and the internalization of stigma. Regardless of their proximity to the self, minority stressors exist as part of a "universe" of stressors, which together are theorized to add to the stress burden of sexual minorities and place them at greater risk for health problems relative to heterosexual individuals (Meyer \& Frost, 2013). Even further, minority stressors have been demonstrated to have a unique negative effect on health and wellbeing that cannot be reduced to stress in general. For example, research has demonstrated that experiences of minority stress are associated with the onset of health problems over time, and the association between minority stress and health remains statistically significant when controlling for exposure to general stressors (Frost, Lehavot, \& Meyer, 2015).

Exposure to minority stressors has been shown in numerous studies to have a persistent and negative impact on the health and wellbeing of LGB people (for reviews and metaanalyses, see Lick, Durso, \& Johnson, 2013; Lucassen, Stasiak, Samra, Frampton, \& Merry, 2017; Meyer \& Frost, 2013). Additionally, research on structural stigma has demonstrated associations between discriminatory social policy (e.g., same-sex marriage prohibitions) and LGB health (for a review, see Hatzenbuehler, 2014). However, emerging research has demonstrated that negative discourses about LGB people that emerge in the context of voter referenda on LGB rights may represent a risk to LGB health and wellbeing, regardless of the policy outcomes of such referenda (Flores et al., 2018; Frost \& Fingerhut, 2016). For example, in a dyadic daily diary study, exposure to negative campaign messages about same-sex marriage in the United States were shown to decrease psychological and relational wellbeing in same-sex couples, even when accounting for the well-known negative effects of daily hassles on couples' wellbeing (Frost \& Fingerhut, 2016).

As Meyer (2003) has outlined, minority stressors exist on a continuum of proximity to the self, ranging from internalized stigma (most proximal) to discriminatory laws and policies (most distal). The negative discourses emerging from policy debates about equal marriage can be located on the more distal 
end of this continuum and may be associated with more proximal forms of minority stress such as expectations of rejection and internalized stigma. Thus, emerging evidence contends that exposure to negative messages about LGB people stemming from political campaigns may represent a unique form of minority stress (Frost \& Fingerhut, 2016), not fully accounted for in the original minority stress model (Meyer, 2003). However, no empirical attempts have been made to distinguish the potential impact of the negative social discourse surrounding marriage debates on mental health from the known impact of existing minority stress processes that are more proximal to the self.

\section{Political Participation and Communities}

The challenges of a political campaign may also be an occasion for people to have a voice and for communities to consolidate. In this section, we examine the role of political participation, defined as any "behaviors that have the intent or the effect of influencing political institutions, processes and decision-making at either the local, regional, national or supranational level" (Barrett \& Zani, 2015, p. 4). Arguably, political participation can help oppressed groups achieve their goals (Amenta, Caren, Chiarello, \& Su, 2010) and it may lead to a sense of empowerment regardless of the achievement of a social movement's explicit goals (Drury \& Reicher, 2005).

Political participation can also foster positive individual outcomes. Upon reviewing the literature, Thomas and Louis (2013) drew the emphatic conclusion that "[p]articipating in collective action is good for emotional wellbeing!" (p. 184). Indeed, activism was associated with several measures of subjective wellbeing in two large US samples (Klar \& Kasser, 2009; Thoits \& Hewitt, 2001) and has also been associated with better health outcomes within a large sample of sexual and gender minority youth (Frost, Fine, Torre, \& Cabana, 2019). Peace activism had positive effects on German teenagers that persisted into adulthood (Boehnke \& Wong, 2011). Moreover, it has been suggested that political participation can buffer the negative effects of exclusion and discrimination. DeBlaere et al. (2014) found that political participation moderated the effect of perceived heterosexism on the distress of sexual minority women of color. Velez and Moradi (2016) similarly found that political participation moderated the negative effect of discriminatory experiences on wellbeing in a large sample of sexual minority adults.

Social support has long been known to foster good health and wellbeing (Schwarzer \& Leppin, 1989). Social support has unique functions in the lives of LGB individuals as compared with heterosexuals, in that it may help them contend with the unique burden of minority stress (Frost, Meyer, \& Schwartz, 2016). Minority stress theory further posits that in order to cope with these unique forms of minority stress, LGB individuals engage in community-level coping processes (Meyer, 2003), for example, accessing an LGB community center for counseling or support groups in coping with antigay violence. Participation within one's local LGB community, and even a sense of psychological connectedness to the community, can ameliorate the negative impact of minority stress (Frost \& Meyer, 2012; Kertzner, Meyer, Frost, \& Stirratt, 2009; McConnell, Janulis, Phillips II, Truong, \& Birkett, 2018). Therefore, some of the benefits of political participation may be explained by the social support and community connectedness inherent in collective action.

\section{The Present Study}

While there is evidence for the impact of political participation, minority stress, exposure to negative campaign messages, and community support on LGB individuals' wellbeing, there is no research on how these factors interact in impacting the wellbeing of sexual minorities during a marriage referendum. Specifically, it is not known if negative campaign messages have an effect on psychological distress above and beyond other minority stress variables: Frost and Fingerhut (2016) found an effect of negative messages on wellbeing, but did not examine the role of other minority stressors. Verrelli et al. (2019) and Ecker et al. (2019) replicated this finding in large Australian samples. Rostosky et al. (2009), on the other hand, integrated exposure to negative campaign messages into a more complex model and found no effect on distress. However, their model only included internalized homophobia as a measure of minority stress, while including separate variables for amendment-related affect, amendment-related conversations, and the (desired or disappointing) outcome of the referendum. Therefore, it is almost certain that the detrimental effect of negative campaign messages is additive to everyday stress, but it is not clear whether it is additive to minority stress. In this study, we ask whether exposure to negative campaign messages is associated with psychological distress in addition to the known effects of other minority stressors (i.e., internalized homophobia, everyday discrimination, and expectations of rejection).

The role of political participation in the context of marriage referenda also needs to be investigated further. Activism has been shown to have a positive effect on wellbeing in general, and this effect has been documented in sexual minorities (DeBlaere et al., 2014; Frost et al., 2019; Velez \& Moradi, 2016). However, no studies (with the exception of a very small effect in Rostosky et al., 2009) have examined the role of political participation during an intensive political campaign, and none have looked at the potential of political participation to buffer the negative effects of the campaign itself. We therefore investigate whether political participation moderates the relationship between exposure to negative campaign 
messages and psychological distress during an equal marriage campaign. We also explore whether political participation has such an effect above and beyond known resources for sexual minorities, such as community connectedness and social support.

\section{Method}

\section{Participants}

Participants were 318 self-identified sexual minority Australians aged 18 years or older. The mean age was 40.06, the median age was 38 , and the standard deviation was 12.38 . The majority, $80.50 \%$, identified as male, $16.35 \%$ as female, and $3.14 \%$ as another gender (nonbinary, agender, queer, genderqueer, etc.). Of all participants, $4.72 \%$ identified with a gender different from the one assigned at birth. Participants used 34 different labels to describe their sexuality; most identified as gay/lesbian/homosexual (88.68\%). Other labels were bi(sexual), queer, ace, pansexual, dyke, poly, celibate, and same-sex. (Five participants who identified as straight or heterosexual were not included in this study.)

We decided not to perform an a priori power analysis, as we deemed it unrealistic to aim for an ideal sample size in a convenience sample of a hard-to-reach population. Random sampling is costly and requires a long duration of recruitment for minority populations, while difficulties in defining sexualities and concerns over stigma make sexual minorities a particularly challenging population to recruit (Meyer \& Wilson, 2009). In light of these practical limitations, we performed a sensitivity analysis, estimating the smallest effects we could detect with our achieved sample size. Assuming a significance level $\alpha=.05$ and a power $\beta=.80$, our sample size was sufficient to detect an effect of $R^{2}=.05$ in a multiple linear regression with ten predictors. In a hierarchical multiple regression adding three final predictors to the previous seven, the sample size is sufficient for detecting $\Delta R^{2}=.03$. The effect sizes found in previous minority-stress studies have been stronger than these (see, e.g., Lucassen et al., 2017). Therefore, the present sample size was determined to be sufficient to test the proposed model.

\section{Measures}

Response options for all instruments were comprised of fivepoint Likert scales ranging from 1 (never) to 5 (very often), unless stated otherwise. Mean summary scores were computed for all measures, unless specified otherwise. The instructions for each scale were reworded so that the duration of the marriage equality campaign was given as a timeframe instead of any other anchors (e.g., the last 12 months). Reliability was assessed for each measure, see Table 1.
Psychological Distress Depression was measured using the Centre for Epidemiologic Studies Depression Scale Revised (CES-D-R10), including ten items (e.g., "My sleep was restless"), two of which were reverse-coded (e.g., "I felt hopeful about the future") (Miller, Anton, \& Townson, 2008). Anxiety was measured with the Generalized Anxiety Disorder (GAD7) scale, comprising seven items (e.g., "Not being able to stop or control worrying"), all positively phrased (Swinson, 2006). For both measures, a total score was computing by summing the items. A higher score on either measure represented more psychological distress.

Exposure to Negative Campaign Messages An eight-item scale was taken and adapted from the diary-based methods used in Frost and Fingerhut (2016). No items were negatively phrased. A higher score indicated more exposure to negative campaign materials. Items included "Saw television commercials against same-sex marriage."

Everyday Stress A ten-item scale was adapted from Cohen, Kamarck, and Mermelstein (1983). Items included "Have you felt that you were unable to control the important things in your life?" Four items were reverse-coded, e.g., "Have you felt that things were going your way?" A higher score represented greater everyday stress.

Internalized Homophobia This first indicator of minority stress was an established scale that contained eight items (Frost \& Meyer, 2009; Meyer, 1995). Items included: "You have tried to stop being attracted to the same sex." A higher score represented stronger internalized homophobia.

Everyday Discrimination This second indicator of minority stress contained eight items, which were adapted from (Williams, Yu, Jackson, \& Anderson, 1997). Items included "How often have you been called names or insulted?" No items were negatively phrased. A higher score indicated more experiences of discrimination.

Expectations of Rejection The final indicator of minority stress included six items measuring rejection (Meyer, Schwartz, \& Frost, 2008). Items were scored from 1 (Strongly disagree) to 5 (Strongly agree). Items included "Most employers would not hire an LGBT+ person." No item was reverse-coded. A higher score represented greater expectations of rejection.

Political Participation Political participation was measured with a 15-item scale by Barrett and Zani (2015). Items included "Vote in elections" and "Write political messages or graffiti on walls." No items are reverse-coded. While some studies identify a distinction between conventional and unconventional behaviors, the current study, along with others (Barrett $\&$ Zani, 2015), is primarily concerned with the overall level of 
Table 1 Means, standard deviations, and correlation coefficients

\begin{tabular}{|c|c|c|c|c|c|c|c|c|c|c|c|c|c|}
\hline Variable & $M$ & $S D$ & $\alpha$ & 1 & 2 & 3 & 4 & 5 & 6 & 7 & 8 & 9 & 10 \\
\hline 1. Depression & 24.72 & 7.98 & .91 & & & & & & & & & & \\
\hline 2. Anxiety & 16.04 & 6.66 & .94 & $.88 * * *$ & & & & & & & & & \\
\hline 3. Age & 40.06 & 12.38 & - & $-.17 * *$ & $-.22 * * *$ & & & & & & & & \\
\hline 4. Exposure & 2.66 & 0.85 & .88 & $.41 * * *$ & $.35 * * *$ & $-.14 *$ & & & & & & & \\
\hline 5. Stress & 2.69 & 0.77 & .89 & $.80 * * *$ & $.82 * * *$ & $-.20 * * *$ & $.36 * * *$ & & & & & & \\
\hline 6. Homophobia & 1.33 & 0.51 & .86 & $.35 * * *$ & $.28 * * *$ & $-.23 * * *$ & $.20 * * *$ & $.25 * * *$ & & & & & \\
\hline 7. Discrimination & 1.60 & 0.59 & .91 & $.63 * * *$ & $.58 * * *$ & $-.16^{* *}$ & $.43 * * *$ & $.57 * * *$ & $.31 * * *$ & & & & \\
\hline 8. Rejection & 2.14 & 0.94 & .92 & $.53 * * *$ & $.47 * * *$ & -.04 & $.31 * * *$ & $.48 * * *$ & $.30 * * *$ & $.51 * * *$ & & & \\
\hline 9. Political & 2.42 & 0.77 & .87 & $.36 * * *$ & $.37 * * *$ & .06 & $.22 * * *$ & $.33 * * *$ & -.02 & $.39 * * *$ & $.23 * * *$ & & \\
\hline 10. Connected & 3.91 & 0.82 & .90 & .03 & .06 & .09 & -.06 & .07 & $-.24 * * *$ & .03 & .02 & $.41 * * *$ & \\
\hline 11. Support & 4.14 & 0.91 & .91 & $-.18^{* *}$ & $-.13^{*}$ & $.15^{* *}$ & -.02 & $-.15^{*}$ & $-.25 * * *$ & $-.14 *$ & $-.21 * * *$ & .03 & $.48 * * *$ \\
\hline
\end{tabular}

Exposure $=$ exposure to negative campaign messages. $* p<.05$. $* * p<.01 * * * p<.001$

political participation. A mean summary score was computed, with a higher score representing greater engagement in political behavior.

Community Connectedness This includes an eight-item scale adapted by Frost and Meyer (2012) from Mills et al. (2001). Items were scored from 1 (Strongly disagree) to 5 (Strongly agree). Items included: "You really feel that any problems faced by the LGBT+ community are also your problems." A higher score represented stronger community connectedness.

Instrumental Social Support To measure instrumental social support, we used the bespoke subscale of the Berlin Social Support Scales (Schwarzer \& Schulz, 2013). Items were scored from 1 (Strongly disagree) to 5 (Strongly agree). It comprised four positively phrased items, such as "There are people who offer me help when I need it." Participants were specifically asked to answer these items with the LGBT+ community in mind. Higher scores indicated a stronger sense of having instrumental support from others.

\section{Procedure}

Participants were recruited via convenience and snowball sampling. Virtually all participants heard of the survey via social media, usually Facebook (70.3\%). They had the possibility to enter a prize draw for one of three vouchers worth AU $\$ 50$ each. The survey had a minimum duration of $4 \min 1 \mathrm{~s}$ and a median duration of $9 \min 17 \mathrm{~s}$.

All measures were presented via the online survey software Qualtrics. Participants were introduced to the study and provided consent. Firstly, the participants answered demographic questions. Then, they complete the outcome measures, followed by exposure to negative campaign messages, everyday stress, and the minority stress scales. Finally, participants were debriefed, and they (optionally) provided contact details for the prize draw.

\section{Results}

Descriptive statistics, Cronbach's $\alpha$ s, and intercorrelations for all measures are reported in Table 1. The continuous variables appeared to be non-normally distributed upon visual inspection. However, non-normality followed expected patterns. Thus, participants in this study experienced relatively low levels of minority stressors and high levels of social support and community connectedness. Such a pattern is to be expected in a country that, like Australia, has a good LGBT rights record; but it also leads to variables being skewed. Since the sample distributions likely reflected population level distributions, we chose bootstrapping as a way to manage non-normality. All analyses below were subject to percentile bootstrapping with $95 \%$ confidence intervals and 5000 samples.

\section{A Priori Analyses: Negative Campaign Messages as a Stressor}

We first examined the hypothesis that exposure to negative campaign messages predicted higher depression and anxiety even when controlling for everyday hassles and minority stress. We therefore conducted a hierarchical multivariate multiple regression analysis with depression and anxiety as the outcome variables. To follow up on this analysis, we also conducted two separate hierarchical multiple regression analyses with depression and anxiety, respectively, as outcomes. See Table 2 . Multicollinearity was not a concern, all VIFs $<2$.

In the first step, demographic control variables were entered into the model. In the second step, exposure to negative campaign messages was entered, and it significantly improved the model, Pillai's $V=0.17, F(2,312)=31.07, p<.001$. Thirdly, everyday stress was entered, but the effect of negative campaign messages remained significant, Pillai's $V=0.05, F$ $(2,311)=9.03, p<.001$. In the fourth and final step, the minority stress variables (internalized homophobia, expectations 
Table 2 Regressions predicting depression and anxiety

\begin{tabular}{|c|c|c|c|c|c|c|}
\hline \multirow[b]{2}{*}{ Step } & \multirow[b]{2}{*}{ Predictor } & \multirow[b]{2}{*}{ Pillai's $V$} & \multicolumn{2}{|l|}{ Depression } & \multicolumn{2}{|l|}{ Anxiety } \\
\hline & & & $b$ & $\beta$ & $b$ & $\beta$ \\
\hline \multirow[t]{4}{*}{1} & (Intercept) & $.52 * * *$ & $31.02 * * *$ & & $22.94 * * *$ & \\
\hline & Male & $.04 * *$ & $-2.88^{* *}$ & -.17 & $-3.21 * * *$ & -.16 \\
\hline & Age & $.05 * * *$ & $-0.10^{* *}$ & -.16 & $-0.11 * * *$ & -.20 \\
\hline & Model & $V=.09 * * *$ & $R^{2}=.04 * * *$ & & $R^{2}=.08 * * *$ & \\
\hline \multirow[t]{5}{*}{2} & (Intercept) & $.22 * * *$ & $19.77 * * *$ & & $15.27 * * *$ & \\
\hline & Male & $.05 * * *$ & $-3.13 * *$ & -.19 & $-3.38 * * *$ & -.20 \\
\hline & Age & $.03 * *$ & -0.06 & -.10 & $-0.08 * *$ & -.13 \\
\hline & Exposure & $.17 * * *$ & $3.77 * * *$ & .48 & $2.57 * * *$ & .33 \\
\hline & Model & $V=.17 * * *$ & $R^{2}=.20^{* * *}$ & & $R^{2}=.18 * * *$ & \\
\hline \multirow[t]{6}{*}{3} & (Intercept) & .02 & -1.73 & & $-3.20 *$ & \\
\hline & Male & .01 & -0.45 & -.03 & -1.08 & -.05 \\
\hline & Age & .02 & $0.04 *$ & .07 & 0.01 & .02 \\
\hline & Exposure & $.05 * * *$ & $1.38 * * *$ & .18 & 0.52 & .06 \\
\hline & Stress & $.63 * * *$ & $7.93 * * *$ & .76 & $6.81 * * *$ & .78 \\
\hline & Model & $V=.63 * * *$ & $R^{2}=.65 * * *$ & & $R^{2}=.67 * * *$ & \\
\hline \multirow[t]{9}{*}{4} & (Intercept) & $.03 *$ & $-3.99 *$ & & $-3.96^{* *}$ & \\
\hline & Male & .01 & 0.25 & -.01 & -0.97 & -.06 \\
\hline & Age & $.02 *$ & $0.05 *$ & .08 & 0.01 & .01 \\
\hline & Exposure & .02 & $0.66^{*}$ & .08 & 0.12 & .02 \\
\hline & Stress & $.50 * * *$ & $6.43 * * *$ & .62 & $5.99 * * *$ & .57 \\
\hline & Homophobia & $.04 * *$ & $1.77 * * *$ & .14 & 0.52 & .04 \\
\hline & Discrimination & $.06 * * *$ & $2.38 * * *$ & .18 & $1.57 * *$ & .12 \\
\hline & Rejection & $.02 *$ & $0.79^{*}$ & .11 & 0.35 & .05 \\
\hline & Model & $V=.16^{* * *}$ & $R^{2}=.70 * * *$ & & $R^{2}=.68^{* * *}$ & \\
\hline
\end{tabular}

Exposure $=$ exposure to negative campaign messages

of rejection, and everyday discrimination) were entered into the model. The effect of negative campaign messages in this model was only marginal, Pillai's $V=0.02, F(2,308)=2.63, p=.073$. An inspection of the confidence intervals for the coefficients in the univariate multiple regressions (Table 2) suggest that the effect of negative campaign messages in Step 4 ([-0.04, 1.42] on depression and $[-0.43,0.75]$ on anxiety) was significantly weaker than in Step $2([2.57,4.79]$ on depression and $[1.69,3.36]$ on anxiety).

\section{A Priori Analyses: Political Participation as a Protective Factor}

Contrary to expectations, more political participation was associated with higher levels of depression, $r(316)=.36, p<.001$; and anxiety, $r(316)=.37, p<.001$. Also contrary to expectations, community connectedness was not correlated with either depression, $r(316)=.03, p=.66$; or anxiety, $r(316)=.06, p=.26$. Only instrumental social support exhibited modest negative correlations with depression, $r(316)=-.18, p<.01$; and anxiety, $r(316)=-.13, p<.05$.

Next, we tested the hypothesis that political participation would buffer the effect of negative campaign messages on depression and anxiety. To this effect, we performed a multivariate multiple regression with depression and anxiety as outcomes. We mean-centered exposure negative campaign messages and political participation and computed their product to assess the interaction. We controlled for age, gender, social support, and community connectedness. See Table 3 for the full results. Contrary to our expectations, higher political participation was associated with higher levels of depression and anxiety, Pillai's $V=0.07, F$ $(2,308)=12.37, p<.001$; and the interaction was nonsignificant, Pillai's $V=0.01, F(2,308)=1.18, p=.307$.

\section{Post Hoc Exploratory Analyses}

Our tests of a priori hypotheses have produced two surprising results. First, while exposure to negative campaign messages was strongly related to distress, this relationship became 
Table 3 Moderation analysis

\begin{tabular}{|c|c|c|c|c|c|}
\hline \multirow[b]{2}{*}{ Predictor } & \multirow[b]{2}{*}{ Pillai's $V$} & \multicolumn{2}{|l|}{ Depression } & \multicolumn{2}{|l|}{ Anxiety } \\
\hline & & $b$ & $\beta$ & $b$ & $\beta$ \\
\hline (Intercept) & $.36^{* * *}$ & $34.26 * * *$ & & $24.44 * * *$ & \\
\hline Male & $.02 *$ & -1.75 & -.10 & $-2.08^{*}$ & -.12 \\
\hline Age & $.04 * *$ & -0.06 & -.10 & $-0.09 * *$ & -.14 \\
\hline Exposure & $.12 * * *$ & $3.16^{* * * *}$ & .40 & $2.03 * * *$ & .26 \\
\hline Political & $.07 * * *$ & $2.73 * * *$ & .26 & $2.45 * * *$ & .24 \\
\hline Exposure*political & .01 & 0.80 & .09 & 0.63 & .07 \\
\hline Connectedness & $<.01$ & 0.01 & $<.01$ & 0.02 & $<.01$ \\
\hline Support & $.03^{*}$ & $-1.40^{* *}$ & -.16 & -0.81 & -.09 \\
\hline Model & $V=.36 * * *$ & $R^{2}=.28 * * *$ & & $R^{2}=.26^{* * *}$ & \\
\hline
\end{tabular}

Exposure $=$ exposure to negative campaign messages

marginal when controlling for other stressors. Second, political participation seemed to enhance distress rather than reduce it.

We therefore explored an alternative model in which political participation was hypothesized to result in higher levels of exposure to negative campaign messages; exposure, in turn, was hypothesized to increase minority stress and everyday stress, thus indirectly leading to higher levels of depression and anxiety. See Fig. 1 for details. The proposed model was tested using structural equation modeling procedures with the lavaan package in $\mathrm{R}$ 3.5.0. The model had a mediocre fit, $\chi^{2}$ $(14)=45.50, p<.001, \mathrm{CFI}=.977, \mathrm{TLI}=.932$, $\mathrm{RMSEA}=.084, \mathrm{SRMR}=.037$. An inspection of the modification indices suggested the need to account for covariance in the residuals of internalized homophobia and the outcome measures. The adjusted model fit the data better than the original model, $\chi^{2}(2)=9.98, p<.01$. The adjusted model also had an acceptable fit (see, e.g., Hu \& Bentler, 1999): $\chi^{2}(12)=$ $35.52, p<.001, \mathrm{CFI}=.983, \mathrm{TLI}=.941, \mathrm{RMSEA}=.079$, $\mathrm{SRMR}=.037$. All direct effects were significant $(p<.05)$,

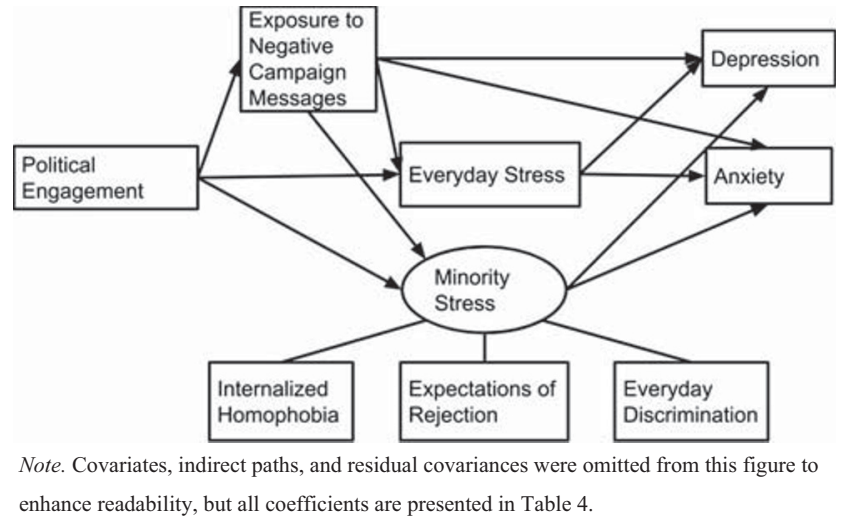

Fig. 1 A model predicting depression and anxiety. Age and gender were included as covariates in all regressions. Covariates, indirect paths, and residual covariances were omitted from this figure to enhance readability, but all coefficients are presented in Table 4. except that exposure to negative campaign messages had no direct effect on depression and anxiety. All indirect paths were also significant (i.e., bootstrapped $95 \%$ confidence intervals did not contain 0 ). Thus, negative campaign messages had a significant indirect effect on depression and anxiety mediated by minority stress and everyday stress. Political participation had both a significant direct effect on minority stress and everyday stress and a significant indirect effect through exposure to negative campaign messages. Since social support and community connectedness were only weakly related to the outcome variables, they were not included in this model. The results are presented in Table 4.

\section{Discussion}

The recent wave of referenda on the rights of same-sex couples has raised questions on the health and wellbeing effects of these votes. We have examined the psychological impact of the same-sex marriage campaign in Australia through the lens of the minority stress model.

The results of this study have confirmed once more the basic tenets of the minority stress model. The key minority stress variables, internalized homophobia, everyday discrimination, and expectations of rejection were associated with higher levels of depression and anxiety; the effect sizes were small to medium. While everyday stress was a strong correlate of depression and anxiety, the minority stress variables remained significant predictors of these emotions even when controlling for everyday stress. Conversely, higher levels of social support were (weakly) associated with lower depression and anxiety.

Apart from the classical minority stress model, we investigated two hypothesized additional mechanisms of distress in sexual minorities. First, we examined whether exposure to negative campaign messages was associated with higher 
Table 4 Results for the structural equation model

$b$

Latent variables

Minority stress

Regressions

Exposure

Anxiety

Depression

Variances

Indirect effects

\section{Perceived discrimination \\ Internalized homophobia \\ Expectations of rejection}

Political engagement

Male

Age

Exposure to negative messages

Political engagement

Male

Age

Exposure to negative messages

Political engagement

Male

Age

Exposure to negative messages

Everyday stress

Minority stress

Male

Age

Exposure to negative messages

Everyday stress

Minority stress

Male

Age

Covariances

Depression
Anxiety
Minority stress

\footnotetext{
Political engagement $>$ exposure to negative messages $>$ everyday stress
}

SE $\quad p$

$p$

Bootstrapped 95\% CI

$\beta$

$\begin{array}{llllll}1.00 & 0.00 & <.001 & 1.00 & 1.00 & .86 \\ 0.38 & 0.07 & <.001 & 0.25 & 0.50 & .38 \\ 1.11 & 0.13 & <.001 & 0.87 & 1.41 & .60\end{array}$

0.

0.22

$0.07<.001$

0.15

0.40

.25

$-0.01$

0.11

.057

$-0.01$

0.45

.10

$-0.01$

0.00

.002

$-0.02$

0.00

$-.16$

0.26

$-0.17$

0.05

$<.001$

0.16

0.34

0.37

0.00

$-0.01$

0.34

0.30

0.08

0.00

0.98

8.48

5.92

1.53

0.11

0.49

7.41

3.92

0.36

0.06

12.79

0.18

0.07

0.28

0.61

0.27

0.14

0.32

0.67

0.77

0.47

22.26

16.07

0.22

0.11

0.11

.07

0.02

.002

0.03

0.12

.11 
Table 4 (continued)

\begin{tabular}{|c|c|c|c|c|c|c|c|}
\hline & & $b$ & $S E$ & $p$ & \multicolumn{2}{|c|}{ Bootstrapped 95\% CI } & $\beta$ \\
\hline & \multicolumn{7}{|l|}{$\begin{array}{l}\text { Political engagement }>\text { exposure to } \\
\text { negative messages }>\text { minority } \\
\text { stress }\end{array}$} \\
\hline & $\begin{array}{l}\text { Exposure to negative messages }> \\
\text { everyday stress }>\text { depression }\end{array}$ & 1.87 & 0.38 & $<.001$ & 1.14 & 2.66 & .20 \\
\hline & $\begin{array}{l}\text { Exposure to negative messages }> \\
\text { everyday stress }>\text { anxiety }\end{array}$ & 1.62 & 0.33 & $<.001$ & 1.00 & 2.33 & .21 \\
\hline & $\begin{array}{l}\text { Exposure to negative messages }> \\
\text { minority stress }>\text { depression }\end{array}$ & 1.06 & 0.26 & $<.001$ & 0.61 & 1.61 & .11 \\
\hline & $\begin{array}{l}\text { Exposure to negative messages }> \\
\text { minority stress }>\text { anxiety }\end{array}$ & 0.62 & 0.20 & .002 & 0.28 & 1.07 & .08 \\
\hline \multicolumn{8}{|l|}{ Total effects } \\
\hline & $\begin{array}{l}\text { Political engagement }>\text { everyday } \\
\text { stress }\end{array}$ & 0.33 & 0.05 & $<.001$ & 0.22 & 0.43 & .33 \\
\hline & $\begin{array}{l}\text { Political engagement }>\text { minority } \\
\text { stress }\end{array}$ & 0.29 & 0.04 & $<.001$ & 0.20 & 0.38 & .44 \\
\hline & $\begin{array}{l}\text { Exposure to negative messages }> \\
\text { depression }\end{array}$ & 3.15 & 0.53 & $<.001$ & 2.15 & 4.25 & .33 \\
\hline & $\begin{array}{l}\text { Exposure to negative messages }> \\
\text { anxiety }\end{array}$ & 2.08 & 0.40 & $<.001$ & 1.34 & 2.87 & .27 \\
\hline
\end{tabular}

levels of depression and anxiety. We found that exposure to negative campaign messages had a detrimental effect in addition to everyday stress, in agreement with the previous literature (Ecker et al., 2019; Frost \& Fingerhut, 2016; Verrelli et al., 2019). However, this detrimental effect did not persist when controlling for known minority stressors (such as everyday discrimination, expectations of rejection and internalized homophobia); we thus provide some clarity on the role of negative campaign messages in the minority stress model, a question that was unaddressed (e.g., Ecker et al., 2019) or only partially addressed (e.g., Rostosky et al., 2009) in the previous literature.

Second, we explored the possibility that political participation during the campaign might buffer LGB people from the detrimental effects of negative campaign messages. Social support and community connectedness had little relevance. We found that more participation was associated with higher levels of depression and anxiety, and there was no evidence for moderation. While the literature has largely supported the positive effect of political participation on wellbeing (for a review, see Thomas \& Louis, 2013), the idea of a toll on activists is not new. Dunn and Szymanski (2018) found that reporting more experiences of discrimination was associated with higher levels of activism, while Rostosky et al. (2009) found a (very small) positive association between activism and distress. Also, activism did not predict the distress levels of trans individuals in the United States (Breslow et al., 2015) or the mental health complaints of gay men in Germany (Sattler, Wagner, \& Christiansen, 2016). Our findings provide further evidence for a negative effect of political participation on wellbeing, at least during intensive political campaigning.
While the result of the postal survey brought tangible benefits for sexual minorities in Australia (i.e., same-sex marriage was approved), these collective gains may have individual costs. Based on these findings, we proposed a new model whereby both exposure to negative messages and political participation increased LGB people's stress, and the effect of these stressors was at least partially mediated by minority stress variables (see Fig. 1). This amended version of the minority stress model was supported by our data, but needs replication in future research.

\section{Limitations and Future Directions}

Our cross-sectional survey offers some insight into psychological mechanisms, but it does not support causal inferences. As Meyer (2003) has noted, it is important to disentangle the measurement of minority stress form the outcomes minority stress is theorized to predict. This issue is particularly pressing when mental health is the outcome of interest, given that individuals with more anxiety and depressive symptoms may be more likely to perceive stressors. We tried to avoid this conflation as much as possible in a cross-sectional design by using measures of mental health and minority stress that were developed with these concerns in mind. Further, previous research using objective indicators of support for same-sex marriage in Australia demonstrated a similar association between voting patterns in the plebiscite and sexual mental health (Perales \& Todd, 2018). Regardless, the present findings can firmly support associations between constructs and invite future research on causal paths. 
Additionally, this study relied on a convenience sample of individuals affected by one particular campaign. The non-probability sample prevents us from generalizing these findings. How votes in other countries might affect local sexual minorities, and whether the same theoretical models can account for their distress, is up for future research. However, it is noteworthy that negative campaign messages have been similarly damaging in the United States (Flores et al., 2018; Frost \& Fingerhut, 2016), and that we found this effect in Australia even as regulations about campaign advertising have been specifically tightened before the postal vote (Marriage Law Survey [Additional Safeguards] Bill 2017).

As a corollary of convenience sampling, our participants were overwhelmingly male and gay. This is likely to have led to a slight underestimation of psychological distress, as depression, anxiety, and low wellbeing are somewhat less prevalent in men than other genders and more prevalent in bisexual people than other sexual minorities (see, e.g., Semlyen, King, Varney, \& HaggerJohnson, 2016). However, the aim of this paper is to explore relationships among constructs rather than to estimate population parameters. Given the practical difficulties of achieving representative sexual minority samples, non-probability sampling is often a necessary compromise for theory-focused studies in this field (for a discussion, see Meyer \& Wilson, 2009). Future research will need to mobilize more resources in order to hone and validate the model on representative samples. This is particularly important as sexual minority individuals who also face other forms of exclusion (such as racism and sexism) may have worse outcomes (see, e.g., sexual minority Black women in the USA; Calabrese, Meyer, Overstreet, Haile, \& Hansen, 2015).

\section{Implications and Conclusions}

Gay rights campaigns and votes are likely to become a global phenomenon in the following years or decades. As of late 2019 , most countries in the world do not allow people of the same gender to marry, and a significant number of countries imprison or even execute people for homosexuality (ILGA, 2019). Nevertheless, change is underway in many countries, favored by economic development, the diffusion of new social norms across borders, and the emergence of gay rights movements (Ayoub, 2016). Therefore, there is an increasing need for evidence-based theories that can inform the public and guide policymaking in the context of these new challenges to the wellbeing of sexual minorities.

The minority stress model is flexible and can respond to new challenges. If previous research (esp. Frost \& Fingerhut, 2016) has articulated the need to study the psychological experience of being exposed to negative campaign messages as a form of minority stress, we are now proposing a specific place for this new stressor in the minority stress model. Specifically, we suggest that exposure to negative campaign messages are a relatively distal stressor, the impact of which is mediated by more proximal stressors. Nevertheless, negative campaign messages create stress for sexual minorities in addition to the pressures of everyday life. The study also suggests that involvement in collective action, rather than protecting sexual minorities, can represent yet another source of stress within the specific context of same-sex marriage referenda. This finding indicates a cost to political activism in efforts to advocate for same-sex marriage and is deserving of future investigation in research on the psychology of activism for minority groups whose rights are being called into question within popular referenda.

Our findings warn of the adverse effects political processes can have on individuals and communities. Putting the rights of minorities up to vote by the majority can create a toxic social environment that can be harmful to those whose social value is put into question by the vote (Flores et al., 2018; Frost, 2020; Frost \& Fingerhut, 2016; Verrelli et al., 2019). Activism, while effective in achieving social change, may create more opportunities for exposure to a variety of minority stressors, which may further diminish the wellbeing of an already at-risk population.

Acknowledgments The authors wish to thank Erik Denison (Monash University, Australia) for his invaluable help in recruiting participants for this study, and Peter Hegarty (University of Surrey, UK) for his advice in the initial stages of the research.

\section{Compliance with Ethical Standards}

Conflict of Interest The authors declare that they have no conflict of interest.

Ethical Approval The research met the ethics self-assessment criteria of the University of Surrey (UK), to which the researchers were affiliated at the time of data collection.

Informed Consent Informed consent was obtained electronically from each individual participant.

Open Access This article is licensed under a Creative Commons Attribution 4.0 International License, which permits use, sharing, adaptation, distribution and reproduction in any medium or format, as long as you give appropriate credit to the original author(s) and the source, provide a link to the Creative Commons licence, and indicate if changes were made. The images or other third party material in this article are included in the article's Creative Commons licence, unless indicated otherwise in a credit line to the material. If material is not included in the article's Creative Commons licence and your intended use is not permitted by statutory regulation or exceeds the permitted use, you will need to obtain permission directly from the copyright holder. To view a copy of this licence, visit http://creativecommons.org/licenses/by/4.0/. 


\section{References}

Amenta, E., Caren, N., Chiarello, E., \& Su, Y. (2010). The political consequences of social movements. Annual Review of Sociology, 36, 287-307. https://doi.org/10.1146/annurev-soc-070308-120029.

Australian Bureau of Statistics (2017). Australian Marriage Law Postal Survey, 2017. Retrieved from http://www.abs.gov.au/ausstats/abs@ . $\mathrm{nsf} / \mathrm{mf} / 1800.0$

Ayoub, P. M. (2016). When states come out: Europe's sexual minorities and the politics of visibility. New York, NY: Cambridge University Press.

Barrett, M., \& Zani, B. (Eds.). (2015). Political and civic engagement: Multidisciplinary perspectives. Hove, UK: Routledge.

Boehnke, K., \& Wong, B. (2011). Adolescent political activism and longterm happiness: A 21-year longitudinal study on the development of micro-and macrosocial worries. Personality and Social Psychology Bulletin, 37, 435-447. https://doi.org/10.1177/0146167210397553.

Breslow, A. S., Brewster, M. E., Velez, B. L., Wong, S., Geiger, E., \& Soderstrom, B. (2015). Resilience and collective action: Exploring buffers against minority stress for transgender individuals. Psychology of Sexual Orientation and Gender Diversity, 2, 253265. https://doi.org/10.1037/sgd0000117.

Calabrese, S. K., Meyer, I. H., Overstreet, N. M., Haile, R., \& Hansen, N. B. (2015). Exploring discrimination and mental health disparities faced by black sexual minority women using a minority stress framework. Psychology of Women Quarterly, 39(3), 287-304. https://doi.org/10.1177/0361684314560730.

Cohen, S., Kamarck, T., \& Mermelstein, R. (1983). A global measure of perceived stress. Journal of Health and Social Behavior, 24, 385396. https://doi.org/10.2307/2136404.

DeBlaere, C., Brewster, M. E., Bertsch, K. N., DeCarlo, A. L., Kegel, K. A., \& Presseau, C. D. (2014). The protective power of collective action for sexual minority women of color: An investigation of multiple discrimination experiences and psychological distress. Psychology of Women Quarterly, 38(1), 20-32. https://doi.org/10. 1177/0361684313493252.

Drury, J., \& Reicher, S. (2005). Explaining enduring empowerment: A comparative study of collective action and psychological outcomes. European Journal of Social Psychology, 35(1), 35-58. https://doi. org/10.1002/ejsp.231.

Dunn, T. L., \& SZYMANSKI, D. M. (2018). Heterosexist discrimination and LGBQ activism: Examining a moderated mediation model. Psychology of Sexual Orientation and Gender Diversity, 5, 13-24. https://doi.org/10.1037/sgd0000250.

Ecker, S., Riggle, E. D., Rostosky, S. S., \& Byrnes, J. M. (2019). Impact of the Australian marriage equality postal survey and debate on psychological distress among lesbian, gay, bisexual, transgender, intersex and queer/questioning people and allies. Australian Journal of Psychology, 71, 285-295. https://doi.org/10.1111/ajpy. 12245.

Family Law Act 1975 (Cth). Retrieved from https://www.legislation.gov. au/Details/C2019C00182

Flores, A. R., Hatzenbuehler, M. L., \& Gates, G. J. (2018). Identifying psychological responses of stigmatized groups to referendums. Proceedings of the National Academy of Sciences, 115, 38163821. https://doi.org/10.1073/pnas.1712897115.

Frost, D. M. (2020). Hostile and harmful: Structural stigma and minority stress explain increased anxiety among migrants living in the United Kingdom after the Brexit referendum. Journal of Consulting and Clinical Psychology, 88, 75-81. https://doi.org/10.1037/ ccp0000458.

Frost, D. M., \& Fingerhut, A. W. (2016). Daily exposure to negative campaign messages decreases same-sex couples' psychological and relational wellbeing. Group Processes \& Intergroup Relations, 19, 477-492. https://doi.org/10.1177/1368430216642028.
Frost, D. M., \& Meyer, I. H. (2009). Internalized homophobia and relationship quality among lesbians, gay men, and bisexuals. Journal of Counseling Psychology, 56(1), 97-109. https://doi.org/10.1037/ a0012844.

Frost, D. M., \& Meyer, I. H. (2012). Measuring community connectedness among diverse sexual minority populations. Journal of Sex Research, 49, 36-49. https://doi.org/10.1080/00224499.2011. 565427.

Frost, D. M., Lehavot, K., \& Meyer, I. H. (2015). Minority stress and physical health among sexual minority individuals. Journal of Behavioral Medicine, 38(1), 1-8. https://doi.org/10.1007/s10865013-9523-8.

Frost, D. M., Meyer, I. H., \& Schwartz, S. (2016). Social support networks among diverse sexual minority populations. American Journal of Orthopsychiatry, 86(1), 91. https://doi.org/10.1037/ ort0000117.

Frost, D. M., Fine, M., Torre, M. E., \& Cabana, A. (2019). Minority stress, activism, and health in the context of economic precarity: Results from a national participatory action survey of lesbian, gay, bisexual, transgender, queer, and gender non-conforming youth. American Journal of Community Psychology, 63, 511-526. https:// doi.org/10.1002/ajcp.12326.

Hatzenbuehler, M. L. (2014). Structural stigma and the health of lesbian, gay, and bisexual populations. Current Directions in Psychological Science, 23(2), 127-132. https://doi.org/10.1177/ 0963721414523775.

Hatzenbuehler, M. L., McLaughlin, K. A., Keyes, K. M., \& Hasin, D. S. (2010). The impact of institutional discrimination on psychiatric disorders in lesbian, gay, and bisexual populations: A prospective study. American Journal of Public Health, 100(3), 452-459.

Healy, G., Sheehan, B., \& Whelan, N. (2015). Ireland says yes: The inside story of how the vote for marriage equality was won. Sallins, Ireland: Merrion Press.

Herek, G. M. (2011). Anti-equality marriage amendments and sexual stigma. Journal of Social Issues, 67, 413-426. https://doi.org/10. 1111/j.1540-4560.2011.01705.x.

Hu, L. T., \& Bentler, P. M. (1999). Cutoff criteria for fit indexes in covariance structure analysis: Conventional criteria versus new alternatives. Structural Equation Modeling: A Multidisciplinary Journal, 6(1), 1-55. https://doi.org/10.1080/10705519909540118.

ILGA (2019). Sexual orientation laws in the world - 2019. Retrieved from https://ilga.org/downloads/ILGA Sexual Orientation Laws Map_2019.pdf

Kertzner, R. M., Meyer, I. H., Frost, D. M., \& Stirratt, M. J. (2009). Social and psychological wellbeing in lesbians, gay men, and bisexuals: The effects of race, gender, age, and sexual identity. American Journal of Orthopsychiatry, 79(4), 500. https://doi.org/10.1037/ a0016848.

Klar, M., \& Kasser, T. (2009). Some benefits of being an activist: Measuring activism and its role in psychological well-being. Political Psychology, 30(5), 755-777. https://doi.org/10.1111/j. 1467-9221.2009.00724.x.

Lick, D. J., Durso, L. E., \& Johnson, K. L. (2013). Minority stress and physical health among sexual minorities. Perspectives on Psychological Science, 8(5), 521-548. https://doi.org/10.1177/ 1745691613497965.

Lucassen, M. F., Stasiak, K., Samra, R., Frampton, C. M., \& Merry, S. N. (2017). Sexual minority youth and depressive symptoms or depressive disorder: A systematic review and meta-analysis of populationbased studies. Australian \& New Zealand Journal of Psychiatry, 51, 774-787. https://doi.org/10.1177/0004867417713664.

Marriage Amendment (Definition and Religious Freedoms) Act 2017 (Cth). Retrieved from https://www.legislation.gov.au/Details/ C2018C00423

McConnell, E. A., Janulis, P., Phillips II, G., Truong, R., \& Birkett, M. (2018). Multiple minority stress and LGBT community resilience 
among sexual minority men. Psychology of Sexual Orientation and Gender Diversity, 5(1), 1-12. https://doi.org/10.1037/sgd0000265.

Meyer, I. H. (1995). Minority stress and mental health in gay men. Journal of Health and Social Behavior, 36(1), 38-56. https://doi. org/10.2307/2137286.

Meyer, I. H. (2003). Prejudice, social stress, and mental health in lesbian, gay, and bisexual populations: Conceptual issues and research evidence. Psychological Bulletin, 129, 674-697. https://doi.org/10. 1037/0033-2909.129.5.674.

Meyer, I. H., \& Frost, D. M. (2013). Minority stress and the health of sexual minorities. In C. J. Patterson \& A. R. D'Augelli (Eds.), Handbook of psychology and sexual orientation (pp. 252-266). New York, NY: Oxford University Press.

Meyer, I. H., \& Wilson, P. A. (2009). Sampling lesbian, gay, and bisexual populations. Journal of Counseling Psychology, 56(1), 23-31. https://doi.org/10.1037/a0014587.

Meyer, I. H., Schwartz, S., \& Frost, D. M. (2008). Social patterning of stress and coping: Does disadvantaged social status confer more stress and fewer coping resources? Social Science \& Medicine, 67(3), 368-379. https://doi.org/10.1016/j.socscimed.2008.03.012.

Miller, W. C., Anton, H. A., \& Townson, A. F. (2008). Measurement properties of the CESD scale among individuals with spinal cord injury. Spinal Cord, 46, 287-292. https://doi.org/10.1038/sj.sc. 3102127.

Mills, T. C., Stall, R., Pollack, L., Paul, J. P., Binson, D., Canchola, J., \& Catania, J. A. (2001). Health-related characteristics of men who have sex with men: A comparison of those living in "gay ghettos" with those living elsewhere. American Journal of Public Health, 91, 980-983. https://doi.org/10.2105/AJPH.91.6.980.

Perales, F., \& Todd, A. (2018). Structural stigma and the health and wellbeing of Australian LGB populations: Exploiting geographic variation in the results of the 2017 same-sex marriage plebiscite. Social Science \& Medicine, 208, 190-199. https://doi.org/10.1016/ j.socscimed.2018.05.015.

Rostosky, S. S., Riggle, E. D., Horne, S. G., \& Miller, A. D. (2009). Marriage amendments and psychological distress in lesbian, gay, and bisexual (LGB) adults. Journal of Counseling Psychology, 56(1), 56. https://doi.org/10.1037/a0013609.

Same-Sex Relationships (Equal Treatment in Commonwealth LawsSuperannuation) Act 2008 (Cth). Retrieved from https://www. legislation.gov.au/Details/C2015C00455
Sattler, F. A., Wagner, U., \& Christiansen, H. (2016). Effects of minority stress, group-level coping, and social support on mental health of German gay men. PLoS One, 11(3), e0150562. https://doi.org/10. 1371/journal.pone.0150562.

Schwarzer, R., \& Leppin, A. (1989). Social support and health: A metaanalysis. Psychology \& Health: An International Journal, 3, 1-15.

Schwarzer, R., \& Schulz, U. (2013). Berlin social support scales (BSSS). Measurement instrument database for the social science. Retrieved from www.midss.ie

Semlyen, J., King, M., Varney, J., \& Hagger-Johnson, G. (2016). Sexual orientation and symptoms of common mental disorder or low wellbeing: Combined meta-analysis of $12 \mathrm{UK}$ population health surveys. BMC Psychiatry, 16(1), 67.

Swinson, R. P. (2006). The GAD-7 scale was accurate for diagnosing generalized anxiety disorder. Evidence Based Medicine, 11, 184. https://doi.org/10.1136/ebm.11.6.184.

Thoits, P. A., \& Hewitt, L. N. (2001). Volunteer work and wellbeing. Journal of Health and Social Behavior, 42, 115-131. https://doi. org/10.2307/3090173.

Thomas, E. F., \& Louis, W. R. (2013). Doing democracy: The social psychological mobilization and consequences of collective action. Social Issues and Policy Review, 7, 173-200. https://doi.org/10. 1111/j.1751-2409.2012.01047.x.

Velez, B. L., \& Moradi, B. (2016). A moderated mediation test of minority stress: The role of collective action. The Counseling Psychologist, 44, 1132-1157. https://doi.org/10.1177/ 0011000016665467.

Verrelli, S., White, F. A., Harvey, L. J., \& Pulciani, M. R. (2019). Minority stress, social support, and the mental health of lesbian, gay, and bisexual Australians during the Australian Marriage Law Postal Survey. Australian Psychologist, 54, 336-346. https://doi. org/10.1111/ap.12380.

Williams, D. R., Yu, Y., Jackson, J. S., \& Anderson, N. B. (1997). Racial differences in physical and mental health: Socio-economic status, stress and discrimination. Journal of Health Psychology, 2, 335351. https://doi.org/10.1177/135910539700200305.

Publisher's Note Springer Nature remains neutral with regard to jurisdictional claims in published maps and institutional affiliations. 